\title{
Coping with Resistance to Faculty Development ${ }^{1}$
}

Jim L. Turner and Robert Boice

California State University, Long Beach

Faculty developers, like the professionals they serve, are susceptible to dysfunctional, job-related stress and diminished enthusiasm for their work. One source of job dissatisfaction for developers lies in the resistance encountered in attempting to present services and programs, especially those that go beyond the awarding of travel money and released time from teaching. Two obvious kinds of resistance, for example, are the typical low level of faculty participation and the numerous objections raised by both faculty and administrators to virtually any program offered.

This paper proposes a proactive approach for faculty developers in seeking to identify and understand the various forms of resistance encountered. Based on our own experience and observations, we provide a preliminary listing of the ways in which resistances are most frequently manifest and suggestions for coping with these more productively.

\section{SUGGESTION OF A MODEL FOR CONCEPTUALIZING RESISTANCE}

Traditional notions about resistance derive from the dynamics of client/therapist interaction (Ellis, 1985; Strean, 1985). While it is not clear that concepts of resistance that emerge in the therapeutic dyad are always of direct relevance in 
faculty development, they offer a reasonable beginning. Typically, the clinical literature identifies three issues in understanding and coping with resistance.

The first issue is the realization that resistance can reveal important information about the individual's needs and suggest forms of intervention. That is, while uncooperative attitudes and behaviors can be frustrating and seemingly unproductive, they also provide insights that might otherwise be unavailable. For example, we find that problematic instructors who resist intervention by blaming their ineffectiveness on student ineptitude typically do not interact with students in or out of the classroom. Simple interventions focused on increasing the frequency of teacher/student contacts often result in significant positive change in both attitude and performance.

The second issue is the need to develop an objective perspective that helps minimize personal reactions to the aversive properties of resistance. This capacity to distance oneself from the emotional content of resistance is as important for faculty developers as for others who provide professional services (e.g., lawyers, physicians, psychotherapists). We find it useful to remind ourselves that our interactions with faculty often involve issues that cut to the core of an individual's sense of competence and self-esteem. That is, resistance is an expected byproduct of an emotionally charged situation. It is part of one's professional role to cope with it objectively but sensitively.

The third issue is to recognize that the providers of help or services can contribute to their own problems by unnecessarily eliciting resistance. Our personal style, the way we present our programs, our beliefs in what works and what doesn't, our own defensiveness toward evaluation and criticism, what we call ourselves (i.e., developers), and other such factors, may be significant as either shortcomings or strengths. An attitude of objective self-scrutiny can provide important insights into the ways we create resistance by unwittingly annoying and alienating faculty.

\section{EXAMPLES OF RESISTANCE TO FACULTY DEVELOPMENT}

In an effort to begin documenting the typical kinds of resistance encountered, we took extensive notes on the comments made by deans and chairs as they responded to new program 
offerings. A content analysis of these data generated a rank ordering of their most common objections. The general types and frequencies of resistances encountered appear quite similar to those we are finding in interviews with newly-hired faculty.

"Faculty are too busy to participate in faculty development!"

Initially, at least, deans and chairs being interviewed (Boice, 1985) about possibilities of arranging developmental programs with their faculty claimed that both they and their faculty were too busy to participate. This sort of finding is not unusual. McKeachie (1979) is among the developers who emphasize the long, hard hours worked by academicians. Not surprisingly, academicians resist new programs that will make demands on schedules that seem already saturated (Boice, 1986). In a study in progress, we have found that newly hired young faculty also invoke time constraints as the major reason for non-participation in workshops and other programs.

"The only program faculty want is released time from teaching."

With almost equal frequency, the same deans and chairs objected to suggestions for programs because they assumed that any meaningful program would require substantial financing and administrative commitment. In fact, most assumed that faculty development could not be done without providing faculty released time from teaching. Here again, parallels can be seen in the accounts of other developers. Kirschling (1979), for example, notes that faculty express strong preferences for developmental programs that include released time and other visible rewards. Gaff (1978), similarly, concludes that faculty resist improvements in areas that don't include financial incentives. Our interviews with new faculty also support this conclusion. Most spent considerable time and effort applying for released time, but avoided other programs.

\section{"They've either got it or they don't."}

This reservation about developmental programs was not nearly so common as the first two, but was far more frequent than we had expected. It seems to stem from the general assumption that teachers and/or scholars are born, not made. We found that chairs and deans expressed this prejudice in a variety 
of forms, among them the assumptions that troubled faculty are largely responsible for their own difficulties and should have known better, are indolent or otherwise morally weak, and should be mature enough to recognize and solve their own problems. Many deans and chairs also indicated that resources would be better spent on more deserving faculty. Developers who have made similar points include Gaff (1978), who reviews the folklore about supposedly inborn qualities of good teachers.

Kindred kinds of negativism about the long-term prospects of developmental programs include recollections that many innovative programs have already fallen into disuse (Davis, 1979), that faculty have difficulty assimilating suggestions for changes (Freedman \& Sanford, 1973), and that faculty participants are often inflexible and unappreciative (Boice \& Myers, in press; Shrock, 1985). One of the most discouraging conclusions comes from the admirably thoroughgoing accounts of Eble and McKeachie (1985): they surmised that the kinds of faculty who typically get help in developmental programs probably would have shown the same results without the external incentives provided.

"Your programs raise issues about faculty's rights to privacy, autonomy, and academic freedom."

The fourth most common objection, concerns about autonomy and related issues, might have been expected to be the most frequent category. And, in a way, it is. We, at least, find that this issue underlies almost every concern about developmental programs. Consider, for example, that for many faculty and administrators, development implies incompetence (Arreola, 1985). Chairs, accordingly, often feel they are being pressured to condone a program that will make faculty feel that they are singled out for remediation (Boice, 1985; in press).

"Faculty don't want help."

Deans and chairs expressed this kind of resistance almost reluctantly. But once they began verbalizing the idea, they showed increasing conviction that many faculty are reluctant to admit to a need for help and too proud to accept it. In this context, deans and chairs often described faculty in terms like "individual entrepreneurs" or "prima donnas." Consistent with 
that image, other developers have noted that faculty, given their own choice of developmental aids, chose tangible benefits like reductions in work load (Leslie, Swiren, \& Flexner, 1977). Unfortunately, many faculty tend to see developmental programs as little more than administrative interference (Gaff, 1978; Lewis \& Becker, 1979).

\section{"How do you know it works?"}

This sixth and final of the commonly stated resistances may have ranked low, in part, because the attitudes involved were ambivalent and difficult to verbalize. That is, deans and chairs seemed to have a general belief that faculty development programs are inherently unsystematic and that the results of such programs might be ephemeral, but had some difficulty in providing specific examples. Indeed, much of the literature on faculty development supports this presumption (Boice, 1984). Even research-oriented developers like Braskamp (1980) recognize that their work lacks clear empirical evidence in areas like quality of teaching, while others emphasize the inherent doublebind in conducting assessments that may also be used for administrative evaluations (Howard, 1977).

Part of the problem is that much of what passes for faculty development (e.g., workshops, released time, etc.) is complicated by a host of uncontrolled variables, and even those variables which are controllable in principle (e.g., sample characteristics) are extremely difficult to manipulate given the practical constraints of the developer's role. Further, it seems likely that faculty development programs are placebo-responsive. This means that the perceived credibility, commitment, and enthusiasm of the developer may play a significant role in the success or failure of a given program, regardless of its actual content or other specified features (Gallimore \& Turner, 1969; Turner, Gallimore, \& Fox-Henning, 1980).

\section{COPING WITH RESISTANCE}

Quick perusal of these common reservations about faculty development programs provides some reminders about the clinical model of resistance proposed earlier. That is, the objectors are evidently suggesting areas in which they would like to see developers provide help. And, with a bit of scrutiny, their 
objections suggest a number of areas where developers themselves are helping generate the resistance.

Given that we have little information on how other developers cope with such resistances, we propose using the model of clinical resistance as a means of generating possible solutions. Briefly, we will focus on each of the three steps: a) what resistance reveals about needed interventions, $b$ ) how to objectify the negative emotionalism involved in resistance, and c) the developers' own contributions to resistance.

\section{What Resistance Says About Needed Interventions}

We have found that, given faculty members' pervasive complaints about too little time, the temptation is to challenge such assertions. Even on initial reflection of what's happening in such an interaction, two things become apparent. First, it rarely helps to become annoyed. A basic rule that psychotherapists learn in eliciting cooperation from patients is not to put patients on the defensive, especially by using guilt-inducing statements (Boice, Andrasik, \& Simmons, 1984). Second, lack of time is often a specious complaint. Busyness is such a salient value in academic subculture that it is routinely employed as a self-presentation strategy regardless of objective time constraints.

So, for example, when administrators and faculty say that they have too little time for faculty development, an appropriate program to offer is one on time management. In fact, recent research shown that academicians often misperceive their time allocations, supposing that they have no time for scholarship when, in fact, they do (Boice, 1986). What these faculty needed instead of the large blocks of free time they imagined essential were ways of setting limits on demands for their time and practical strategies for using their available time more efficiently.

Similar insights can be obtained from other types of resistance. In the case of complaints about insufficient finances, administrators may be especially receptive to cost-effective innovation in program designs. With the complaint that faculty can't change, the message to the developer may be that administrators confuse their own assumptions about faculty attitudes with an inability to change. When the complaint concerns faculty autonomy, administrators often are unnecessarily cautious or reluctant to provide necessary help. 
On the other hand, faculty who decline developmental programs in the name of autonomy may in fact be demonstrating their mistrust of administrators (Boice, in press).

Finally, objections that faculty development cannot be empirically assessed may be a clue the individuals making the complaint need education about recent research in faculty development. While there is some truth to the assertion that faculty development programs are rarely evaluated and that gains are often temporary, in principle, this area is no more immune to measurement than other disciplines in the social sciences.

\section{How to Cope with the Aversive Properties of Resistance}

In essence, the coping strategy here entails a new perspective on what could otherwise be troublesome interactions. The developer must expect resistance and even welcome it. He or she must, ideally, choose to study the objections as though collecting evidence about interesting interactions. When a developer is in that role of seeing even the most emotional objections as yet more interesting data, he or she remains remarkably calm. Along with that serenity, at least two other benefits accrue: the other person also remains calm, and the developer maintains a more objective stance. Ansel Adams (1985) recalls having learned a similar value in maintaining a "clinical attitude:" "To this day, when under stress I find myself dispassionately observing people and their reactions as well as my own" (p. 161). Adams' skill as a photographer, some of which he attributes to this ability for "distancing," helps dispel concerns that a clinical attitude must interfere with communication.

In our own experience of proposing developmental programs, one administrator reacted almost immediately with a comment about faculty development being a boondoggle. This less than diplomatic attitude is not uncommon. Rather than becoming defensive, we chose instead to agree that we could understand his feeling and encouraged further elaboration. What emerged was a rich and frank discussion of his perceptions of faculty development. We also chose to interpret his comments as indicating a need for intervention (e.g., a systematic program for education administrators about the basics of our programs). 


\section{What Resistance Can Tell You About Yourself}

In the usual process of learning to analyze and cope with resistance from others, the analyst begins to discover that his/her own feelings and behaviors may contribute to or encourage resistant responses. Whenever serious resistance to developmental programs is encountered, the developer should actively look for his/her own contribution to it. One way to discover possibilities for such reactions is to routinely solicit faculty and administrator feedback on program offerings. Programs may be perceived as foolishly idealistic, as evangelistic, as irrelevant to current needs, as unduly demanding and impractical, etc.

A particularly effective means of learning about one's own tendencies to elicit resistance is a simple social skills strategy (Curran \& Monti, 1982). It begins with the counter-intuitive ploy of finding a way to agree with criticism, no matter how inappropriate or unfounded it may seem. The developer in this role should maintain an attitude of sincere interest while asking the critic for further elaboration of all feelings and experiences which help to clarify the critic's objections. With this accomplished, critical feedback can be utilized constructively for program evaluation, and the probability of developing a sense of mutual respect and trust in one another's professionalism is enhanced.

As a rule, the last part of this process that emerges when developers practice objective analysis of resistance is recognition that they bring their own sets of negative biases to their work. For example, developers may unwittingly communicate personal attitudes and beliefs that seem a) counterproductive (e.g., cynicism, grandiosity, self-righteousness, etc.), b) resistant to evaluation of the relevance and efficacy of their programs, c) overreactive (favorably or unfavorably) to individuals, and d) blameful of others for all problems or failures. We occasionally find ourselves in this pose. But then, because we actively work at defusing and learning from such realizations, this procedure often functions as an effective antidote to the disillusioning aspects of our work.

\section{DISCUSSION}

Overall, these considerations suggest that some of the frustrations encountered in faculty development can be viewed 
more constructively. While it is easy to become discouraged by negative responses to programs, adopting the model proposed here can help in three ways: first, this perspective helps developers conceptualize and cope with their own occupational frustrations and avoid burnout; second, it helps sensitize developers to their own characteristic modes of reaction as a major contributor to the problem; third, systematic documentation of resistance provides a valuable opportunity for ongoing collection of naturalistic data and a better understanding of the varying perspectives and concerns of faculty and administrators.

Further, adopting this approach suggests other potentially useful ways of looking at resistance to faculty development. Some of these include: 1) The difference between active and passive resistance (i.e., the kinds of resistance listed in the rankordering above were expressed as active resistance; passive sorts of resistance may be evidenced in more subtle forms-e.g., a high incidence of unreturned phone calls and/or broken appointments). 2) The importance for the developer of learning to use his or her own emotional reactions to resistance as a clue that more objective analysis needs to be utilized. So, for example, maintaining a diary of critical incidents and one's own reactions and feelings could be instructive in this regard. 3) The realization that manifest resistances may reflect underlying values and themes which might not otherwise be readily perceived or understood (Deshler, 1985).

Many faculty developers occupy a marginal role status in academic subculture (i.e., neither faculty nor administrators). This marginality, while problematic and often a source of resistance, also offers a unique opportunity to document and examine faculty/administration conflicts from a more detached wholistic perspective. Adopting the role of ethnographer can create opportunities for making significant research contributions to our discipline while at the same time enhancing professional effectiveness and personal well-being.

\section{REFERENCES}

Adams, A. (1985). Ansel Adams: An autobiography. Boston: Little, Brown and Company.

Arreola, R.A. (1985). Establishing successful faculty evaluation and development programs. In Al Smith (Ed.), Evaluating Faculty and Staff (pp. 83-93). San Francisco: Jossey-Bass. 
Boice, R. (1984). The relevance of faculty development for teachers of psychology. Teaching of Psychology, 11, 3-8.

Boice, R. (1985). Differences in arranging faculty development through deans and chairs. Research in Higher Education, 23, 245-255.

Boice, R. (in press). Faculty development via field programs for middleaged, disillusioned faculty. Research in Higher Education.

Boice, R. (1986). Is released time an effective component of faculty development programs? Manuscript submitted for publication.

Boice, R., Andrasik, F., \& Simmons, W.L. (1984). A process account of establishing rater reliability with the Matarazzo Checklist of Therapist Behavior. Teaching of Psychology, 11, 110-111.

Boice, R., \& Myers, P. (in press). Stresses and satisfactions of chairing in psychology. Professional Psychology.

Braskamp, L.A. (1980). The role of evaluation in faculty development. Studies in Higher Education, 5, 45-54.

Curran, J.P., \& Monti, P.M. (Eds.) (1982). Social skills training. New York: Guilford.

Davis, R.H. (1979). A behavioral change model with implications for faculty development. Higher Education, 8, 123-140.

Deshler, D. (1985, November-December). Metaphors and values in higher education. Academe, 71(6), 22-28.

Eble, K.E., \& McKeachie, W.J. (1985). Improving undergraduate education through faculty development. San Francisco: Jossey-Bass.

Ellis, A. (1985). Overcoming resistance: rational-emotive therapy with difficult clients. New York: Springer Publishing Company.

Freedman, M., \& Sanford, N. (1973). The faculty member yesterday and today. New Directions for Higher Education, 1, 1-16.

Gaff, J.G. (1978). Overcoming faculty resistance. New Directions for Higher Education, 24, 43-57.

Gallimore, R.G., \& Turner, J.L. (1969). Faith and psychotherapy: Some problems in theories of psychotherapy. In D.A. Hansen (Ed.), Explorations in sociology and counseling (pp. 93-116). Boston: Houghton Mifflin.

Howard, George S. (1977). A program to improve university instruction: A promising area for psychologists. Professional Psychology, 8, 316-327.

Kirschling, W.R. (1979). Conceptual problems and issues in academic labor productivity. In D.R. Lewis \& N.E. Becker (Eds.), Academic rewards in higher education. Cambridge, MA: Ballinger.

Leslie, L.L., Swiren, J.M., \& Flexner, H. (1977). Faculty socialization and instructional productivity. Research in Higher Education, 7, 127-143. 
Lewis, D.R., \& Becker, W.E. (Eds.) (1979). Academic rewards in higher education. Cambridge, MA: Ballinger.

McKeachie, W.J. (1979). Perspectives from psychology: Financial incentives are ineffective for faculty. In D.R. Lewis \& W.E. Becker (Eds.), Academic rewards in higher education. Cambridge, MA: Ballinger.

Shrock, S.A. (1985). Faculty perceptions of instructional development and the success/failure of an instructional development program: a naturalistic study. ECTJ, 33, 16-25.

Strean, H.S. (1985). Resolving resistances in psychotherapy. New York: John Wiley \& Sons.

Turner, J.L., Gallimore, R.G., \& Fox-Henning, C. (1980). Placebo: An annotated bibliography. JSAS Catalog of Selected Documents in Psychology, 10, 33. (Ms. No. 2063)

\section{NOTES}

1. This paper was originally presented at the 1985 Professional and Organizational Development Network in Higher Education Conference held at Delavan, Wisconsin. 